\title{
GORDON RESEARCH CONFERENCE ON INORGANIC CHEMISTRY
}

\section{New England College, Henniker, New Hampshire, 21-26 July, 1996}

David L. Thorn (DuPont), Chair; Andrew Barron (Rice University), Vice-Chair

Sunday evening, 21 July 1996,

7:30 Welcome; introductory remarks

Coordination Chemistry, part 1: A Celebration of Varied Coordination Environments Nadine de Vries (DuPont), Discussion Leader

Frank Feher (University of California, Irvine): "Coordination Chemistry of Silsesquioxanes: The Good, the Bad, and the Ugly"

Helmut Schwarz (Berlin): "Bond Activation by 'Bare' Transition Metal lons: An Intersection of Theory and Experiment"

Kit Cummins (Massachusetts Institute of Technology): "New Bond Cleavage and Atom Transfer Reactions of Low-Coordinate Complexes"

Monday morning, 22 July

9:00 Main-group and Cluster Chemistry

Peter Dorhout (Colorado State), Discussion Leader

Steve Strauss (Colorado State University): "Fluorinated Polyhedral Heteroboranes as Weakly Coordinating Anions"

Richard Holm (Harvard University): "Metal Clusters in Biology"

Mercouri Kanatzidis (Michigan State University): "Recent Developments in the Solid State Chemistry of Metal Chalcogenides"

Moungi Bawendi (Massassachusetts Institute of Technology): "Semiconductor nanocrystallites: from isolated quantum dots to complex structures"

Monday evening, 22 July 1996

7:30 Catalysis and Catalysts

Jerry Ebner (Monsanto), Discussion Leader

Richard Kemp (Shell): "Recent Work in Polyolefin Catalysis"

Elisabeth Bordes (Compiègne): "Heterogeneous Catalysis in Selective Oxidation of Hydrocarbons: from Bulk, Crystalline to Supported, Monolayered Catalysts"

Jo Ann Canich (Exxon): "Single-Site Catalysts for Olefin Polymerization"

Tuesday morning, 23 July 1996

9:00 Surfaces, Particles, and More Clusters

Norm Herron (DuPont): "Molecular Precursors to Functional Materials"

Mike Sailor (University of California, San Diego): "Surface Chemistry of Luminescent Porous Silicon"

Ken Klabunde (Kansas State University): "Unique Surface Chemistry of Nanoparticles of Metal Oxides and Layered Metal Oxides"

Terry Turney (CSIRO, Australia): "Mechanical Activation of Chemical Processes" 
Tuesday evening

7:30 Deposition Chemistry

Andrew Barron (Rice University), Discussion Leader

Wayne Gladfelter (University of Minnesota): "Chemical Vapor Deposition of Metallic Compounds"

Chuck Winter (Wayne State University): "Chemistry of Precursors to Metal Nitride Films"

Tony Jones (Epichem LTD, U.K.): "Developments in Metalorganic Precursors for Vapour Phase Epitaxy"

Wednesday morning, 24 July 1996

9:00 Coordination Chemistry, part 2: Electrons, Photons, and Radicals

Kim Dunbar (Michigan State University), Discussion Leader

Dan Nocera (Michigan State University): "Optical Supramolecules"

Dave Tyler (University of Oregon): "Cage Effects in Inorganic Radical Chemistry"

Arne Vogler (Regensberg): "Charge Transfer Excited States of Transition Metal Complexes and Implications for Bioinorganic Chemistry and Catalysis"

Chuck Grissom (University of Utah): "The Role of Magnetic Spin in B-12 Dependent Enzymatic and Photochemical Reactions"

Wednesday evening

7:30 Inorganic Chemistry in Biological Systems

Jacqueline Barton (California Institute of Technology): "DNA-mediated Electron Transfer with Metallo Intercalators"

Julie Kovacs (University of Washington): "Structure and Reactivity of Models for Sulfur-Ligated Sites of Metalloenzymes"

Scott Cunningham (DuPont): "Phytoremediation of Soils Contaminated with Heavy Metals"

Thursday morning, 25 July 1996

9:00 New Solids

Robert Haushalter (NEC Research): "Hydrothermal Synthesis of Organically Templated Vanadium Oxide andVanadium Phosphate Solids"

Neil Bartlett (University of California, Berkeley): "The Preparation of Thermodynamically-Unstable Transition Metal Fluorides and their Remarkable Oxidizing Properties"

Mike Whangbo (North Carolina State University): "Surface Analysis with Scanning Tunneling and Atomic Force Microscopy"

David Mitzi (IBM): "Organic-Inorganic Perovskites"

Thursday evening

7:30 Business meeting

Francis Via (Akzo-Nobel): "The Global Research Enterprise: Leveraging Resources"

Jay Labinger (Beckmann Institute - California Institute of Technology): "Science and its Critics" 